\title{
Correspondence
}

\section{College Delegation to South Africa, February 1990}

DeAR SIRS

We are concerned that the Council failed to see the implications of continuing the visit in opposition to the request of the ANC to postpone it. There were no clear terms of reference and there was inadequate preparation and consultation.

We ask Council for a clear statement of how the delegation was chosen, how it was briefed and whom it sought to meet.

We anticipate the delegation's report will be motivated more by a desire to be scrupulously fair to the Society of Psychiatrists of South Africa than to apply pressure for a fundamental change in the apartheid system of mental health care.

What will be most helpful for those psychiatrists in South Africa who are trying to achieve a nondiscriminatory psychiatric service would be a report that defines the terms of reference of the delegation, the specific steps needed to challenge the apartheid system of psychiatry and to collaborate in promoting change, and the practical criteria by which it can be judged whether the SPSA has made sustained efforts or merely gestures.

For example it should report on whether the SPSA has a code of conduct which prohibits apartheid practices, whether there are disciplinary procedures to implement it, and the criteria under which disciplinary action would be taken against psychiatrists, including government advisers, and SPSA members working with the police, prosecution and armed services, who are perpetuating apartheid practices in mental health.

C. BURFORD

S. FERNANDO

D. Hollander

St Ann's Hospital

A. KAPLAN

London N15 3TH

\section{Dear Sirs}

Dr Burford and his colleagues should wait to see the report of the College delegation, which is in preparation, and will be considered by Council in October.

I entirely reject their allegations that the delegation were inadequately prepared.

In the meanwhile they might like to read the report of the (1989) visit of the American Association for the Advancement of Science, which was published in South Africa at the time of our delegation's visit and which received widespread support from the many different organisations which our delegation met there. It will certainly be endorsed by our College.

Its first recommendation reads as follows:

"End apartheid. Any measures short of shared and fully representative political power will fail to correct the serious discrepancies in economic and social status, education, housing, access to health services, basic nutrition, and public health programmes which create the marked differences in health conditions among racial groups in South Africa."

DR J. L. T. BIRLEY President,

July 1987-July 1990

\section{Clinical audit made easier using computers}

\section{DeAR SIRS}

In his thoughtful article on clinical audit (Psychiatric Bulletin, May 1990, 14, 275-277) Dr Brian Ferguson writes that it "is clearly impossible for busy routine services" to "carry out detailed structured interviews of mental state throughout treatment programmes in order to measure clinical effectiveness". This has indeed been true until now, but the current development of computerised clinical audit programs at the Maudsley Hospital and Institute of Psychiatry is making the formerly impossible become feasible. Using computers, routine meaningful clinical audit is carried out so that clinicians can rapidly follow the progress of individual patients and groups of patients on clinical criteria. Clinical progress is printed out on charts that resemble temperature, blood pressure or ECG charts in general medicine, and the broad cost of treatment to attain that progress is printed at the same time. In this way the clinician can track the patient's improvement and the expenditure of resources to attain that state until that point. Use of appropriately programmed computers to achieve this requires little time from the clinician and patient, and the computers are inexpensive and becoming steadily cheaper. When they are further developed we hope to make the programs more generally available in the future.

Institute of Psychiatry

ISAAC MARKS 